$1-1-2012$

\title{
The Eyes and Ears of Engagement: Using RAs to Assess Resident Engagement
}

Curtis R. Naser

Fairfield University, cnaser@fairfield.edu

Karen Donoghue

Fairfield University, kdonoghue@fairfield.edu

Stephanie L. Burrell Storms

Fairfield University, sstorms@fairfield.edu

Copyright 2012 The Pennsylvania State University Press. This article is used by permission of The Pennsylvania State University Press. All rights reserved.

\section{Peer Reviewed}

\section{Repository Citation}

Naser, Curtis R.; Donoghue, Karen; and Burrell Storms, Stephanie L., "The Eyes and Ears of Engagement: Using RAs to Assess Resident Engagement" (2012). GSEAP Faculty Publications. 118.

http://digitalcommons.fairfield.edu/education-facultypubs/118

\section{Published Citation}

Naser, Curtis R., Karen Donoghue, and Stephanie Burrell. "The Eyes and Ears of Engagement: Using RAs to Assess Resident Engagement." Journal of Assessment and Institutional Effectiveness 2, no. 2 (2012): 196-210. doi:10.5325/jasseinsteffe.2.2.0196 .

This Article is brought to you for free and open access by the Graduate School of Education \& Allied Professions at DigitalCommons@Fairfield. It has been accepted for inclusion in GSEAP Faculty Publications by an authorized administrator of DigitalCommons@Fairfield. For more information, please contact digitalcommons@fairfield.edu. 


\title{
The Eyes and Ears of Engagement: Using RAs to Assess Resident Engagement
}

\author{
CURTIS R. NASER, KAREN DONOGHUE, AND STEPHANIE BURRELL
}

\section{ABSTRACT}

This article analyzes the effectiveness of an effort to assess the extent of student engagement at Fairfield University through the assistance of resident assistants (RAs) and the adaptation of a methodology used by the university's schools of engineering and education. Asking RAs to participate in an assessment of their residents provides several clear benefits: the assessment rubric sets clear expectations in plain language; the rubric sets out clear expectations to the residents; and the assessment data appear to be a valid indicator of student engagement and allow the institution to identify students who may benefit from additional counseling or attention.

\section{Set-Up}

At Fairfield University our strategic plan, adopted in 2005, calls for the integration of living and learning. Learning Reconsidered: A Campus Wide Focus on the Student Experience (Keeling 2004) suggests that Student Affairs professional and paraprofessional staff play a significant role in creating and educating students on the broader campus curriculum, bridging the gap between the classroom and out-of-classroom experiences. In particular, live-in professional staff and student resident assistants (RAs) have the potential to positively influence students' classroom

JOURNAL OF ASSESSMENT AND INSTITUTIONAL EFFECTIVENESS, Vol. 2, No. 2, 2012

Copyright (C) 2012 The Pennsylvania State University, University Park, PA 
and social success, if the residence hall community engages students in smaller dialogues through formal programming and mentoring opportunities (Parks 2000).

Our Office of Residence Life over the last four years has tried to create small intentional communities, managed by the student RA (one per residence hall floor) and the professional area coordinator (one per building). These smaller environments tend to best challenge and support our students in their academic pursuits. Within these small communities, we have the opportunity to engage daily in conversations with many of our residents about academic and social life on campus. Kuh et al. (2005) found that students who are more engaged with their residential hall community are more likely to succeed in academic and extracurricular life. According to Kuh et al., if students are engaged in life outside of the classroom (in mentoring communities or floor programs) they are more invested in their educational experience, which will positively affect their academic life. It has also been demonstrated that if students are engaged in programs outside of the classroom, students will more likely than not be invested in the school until they graduate.

With these initiatives underway to better integrate students' residence hall experiences with their academic learning and to engage students in community-building experiences, we sought a way to measure student engagement. While more traditional national surveys such as the National Survey of Student Engagement (NSSE) provide a onetime snapshot of student engagement in co-curricular and academic life, these instruments are expensive to administer and do not provide real-time assessment of individual student experiences (we administer the NSSE every three years at Fairfield, alternating with other national survey instruments). Nor do these instruments typically provide timely feedback on individual students that might be used to improve their experiences or address specific needs.

Both our schools of engineering and education employ an assessment methodology that applies programmatically defined rubrics to individual students. These rubrics are typically employed by faculty to assess the competencies (engineering) or dispositions (education) of their students as they move through their respective programs of study. We thought this model was well suited to the needs of Residence Life and that we had a population of RAs who know their resident students as well as any other institutional representative on campus. Our RAs live on the residence hall floor with between twenty and forty residents. They know each resident personally 
and are trained to support their residents both individually and as a group, and the RAs are actively promoting co-curricular and community-building activities with their residents.

\section{How}

Our Facilitator for Academic Assessment (Naser) worked with the Director of Residence Life (Donoghue) to develop a nine-trait assessment rubric that focuses on resident engagement in the academic, co-curricular and residence hall communities. Five traits on the rubric focus on engagement and an additional four traits focus on the student's relationship to the RA. We employed the standard Strongly Disagree-Strongly Agree scale on each of the nine traits:

\section{Resident Engagement}

I. Resident is engaged in academics

2. Resident is engaged in floor programs

3. Resident is engaged in floor community

4. Resident is engaged in co-curricular life

5. Resident is present on floor

\section{Resident Relationship}

6. Resident has a mature response to RA authority

7. Resident shows respect for other residents

8. Resident seeks out RA resources

9. I (RA) have a good relationship with this resident.

Since RAs would be completing this rubric on each of their residents and the number of residents can run up to forty, we wanted to make sure that the rubric was not overly detailed and burdensome on the RAs to complete.

Fairfield University has over 2,500 undergraduate students in residence under the supervision of 60-70 RAs. Residents live in traditional residence halls, apartments, and townhouses, with the bulk of the first- and second-year classes in traditional residence halls. Approximately 400 seniors live off campus and we have a small contingent of full-time commuter students ( 60$)$.

Attempting to survey each of these 2,500 resident students (each semester) would be costly and time-consuming and distract from other surveys we ask them to complete each year. Asking 6o+ RAs to complete this 
nine-trait rubric is a much more manageable task, though it too presents challenges in preparing and distributing the rubric and collecting the data.

The Mentor Online Course Management and Assessment System (originally named "Eidos") was developed at Fairfield University to manage assessment of student learning outcomes across the curriculum of all our schools and programs. The Mentor system is designed to integrate a variety of assessment practices into a full-featured online course management system, including the deployment and scoring of programmatically defined rubrics across multiple course sections.

We worked with our Banner support staff to create additional "courses" in the Mentor system whose rosters would be populated by student residence-hall assignments. Each residence hall floor gets its own course with the RA as instructor. The Mentor assessment module allows an administrator to push any specific assessment rubric into any set of courses desired. Thus, we are easily able to place the RA assessment rubric into each RA course and the RA thus has an assessment rubric for each student in the class. The RAs are not required to do any set-up work for the assessment, ensuring that the assessment rubric is the same for all RAs and residents.

Because we are using the same "student assessment" system as is in use already by our schools of engineering and education, we have a set of reports built into the Mentor system that automatically summarize the assessment data in a number of ways, comparing results by residence hall floor and allowing us to drill down to the data on each individual resident (more on this below).

In short, we are set up to collect RA assessments of several thousand residents each semester at virtually no cost to the institution beyond the base cost of supporting the Mentor system. And because the data entry takes place at the point of assessment-each RA completing an electronic rubric on each resident - results are available instantly. There are no printing costs, administrative staff costs, data entry costs, or data analysis costs. All these processes are electronic and automated.

\section{Identifiers, Privacy, and Possibilities}

By using the Student Assessment module of the Mentor system, which is designed to track assessment data at the individual student level as well as aggregate that data for review at the classroom (residence hall floor) and program levels, the assessment data produced by our RAs are all individually 
identifiable data. The Mentor system automatically tracks the resident identity and links it to the rubric scores, and of course the RA's identity is linked as well, since each rubric is applied in the context of a unique Mentor course (residence hall) to which the RA is assigned as instructor.

The linking of student identifiers to this assessment data is systematic and reliable. It does not rely upon individuals to report identifiers. Unlike self-reported identifiers on standardized surveys, we can have Io०\% confidence that the identifiers on the data are correct. Nor is there any selection bias built into the identifiers since there is no "opt out" for the residents. The residents being assessed are, in fact, not involved in the process at all.

Using the unique identifier assigned to each student, the Mentor system is able to join the data on each trait in our RA assessment rubric to each student's academic record. Mentor automatically builds a table of each student's term GPA based on the course registration and grade data downloaded into Mentor from Banner, and these data are linked within Mentor, along with a host of enrollment variables (e.g., ethnicity, class year, gender). We thus have a very rich data set with which to analyze the connections between what the RAs assess and who the students are and how they perform at our institution.

The individually identified rubrics provide the institution with indicators of individual resident engagement. Provided that the RA assessments can be demonstrated to be valid indicators of student outcomes at the institution, this data provides real-time evidence of student success and, perhaps more important, students at risk. Just as our professional schools rely on direct assessments of student skills, competencies, and dispositions to evaluate student readiness to proceed in their respective programs as well as identify students in need of additional assistance, so this RA assessment data may provide an early indicator of individual student issues that timely intervention by professional staff may help resolve.

Anytime we collect identifiable data there come responsibilities to protect these data, use them wisely, and make sure that those about whom the data are collected understand their purposes and uses. Assessment data have two primary uses: to improve the curriculum, programs, and learning outcomes of our students as a whole, and, where feasible, to assist us in improving the learning outcomes and experiences of our individual students. We inform our resident students that their RAs will use the ninetrait assessment rubric each semester to assess their residents on each residence hall floor. We inform the resident students that we use these data to improve programming in the residence halls, improve RA training, and 
to help the institution identify individual students who may not be fully engaged in their residence hall life.

We do not report RA assessment scores back to the residents. We want our RAs to provide a frank and honest assessment without the burden of having to justify their judgments to the individual residents being assessed. We also want to make sure that our residents understand that the RA assessment data are not a grade, or any sort of hoop they must jump through. RA assessments are held confidential by the Residence Life staff and used for aggregate program evaluation as well as to assist the professional Residence Life staff in identifying individual students who might benefit from additional attention. (See below for an account of how this data is used by Residence Life professional staff.)

Finally, RAs themselves are counseled that the data they produce in their assessments are not used to evaluate their own performance as RAs, for this introduces an obvious conflict of interest. We want the RAs to provide an honest and candid assessment of their residents, and this would not be possible if they knew that their own performance was in some way being assessed by the data they themselves are reporting on their residents.

\section{Execution}

We initiated this RA assessment project in the spring semester of 2008 . Our rubric was developed by a small committee of Residence Life staff with the aid of the Facilitator for Academic Assessment. The rubric was shared with other professional staff in Residence Life, including the area coordinators, each of whom is assigned a single residence hall. We pilot-tested the rubric and the electronic deployment of it with our freshman class and their RAs that first spring.

Because this project was developed over the spring term of 2008 , we did not have a great deal of time to prepare our RAs on the project and we chose to pilot-test it with just the freshmen RAs. Late in that term, we ran two training sessions: 27 RAs had freshmen residents and 23 completed the assessments on 673 residents. We found that the RAs' innate facility with online systems largely obviated more than the most basic introduction and training on the Mentor system. During the training sessions, we found the RAs were already filling out their assessments, even as we were explaining to them how to do so. The RAs found the assessment rubric easy to complete. Most reported assessing their thirty or so residents in about an hour. 
An interesting side benefit to using the Mentor system was immediately discovered: the RAs found that the Mentor system automatically had a class email system available to them for use at any time. RAs had been struggling to collect resident email addresses to be able to notify their residents of upcoming events, meetings, and other announcements. They quickly realized the potential of having a full online course management system at their fingertips for facilitating communications with their residents. They are able to post announcements and documents as well as use the builtin group email functions. Some have even initiated use of the discussion board with their residents. To our knowledge, RAs have not yet assigned any papers!

The freshmen RAs in that first round had not been apprised of this project prior to the initial invitation to participate at the end of the spring 2008 semester. To prepare our RAs in the following year, we took an hour out of their intensive one-week training prior to the fall 2008 semester to talk to the RAs about the project and what was required of them, show them the rubric, and show them how to access the Mentor system to complete their assessments.

For the 2008-2009 year we broadened the assessments to all residents except the seniors. We collected I,768 assessments by fifty-seven RAs in the fall of 2008 and I,II4 assessments by thirty-two RAs in the spring of 2009. We learned a valuable lesson that second spring semester: the end of the term is a distracting time for RAs, especially if they are graduating. For subsequent semesters, we have asked the RAs to do their assessments about two-thirds of the way through the semester. This gives us time to follow up with the RAs who have not completed their assessments and, perhaps more importantly, to follow up with individual students who are rated particularly low on these assessments.

Fall 2009 (the most recent semester as of this writing)—saw I,984 residents assessed by sixty-eight RAs. We included the seniors this time, but RAs in the "townhouses" on our campus do not know all of the residents of the townhouses not in their immediate townhouse block. We asked them to assess only those residents they know and in whom they are confident in their assessments.

In addition to the introduction to the RA assessment project that we made during the late August 2009 RA training session, we conducted a "norming" session with the RAs just before Thanksgiving 2009. We brought the RAs together (fed them pizza), showed them some of the results of the previous RA assessments, and, while seated at tables of six 
to eight RAs, asked them to discuss each trait (question) on the rubric and come up with indicators of each point on the scale (Strongly DisagreeStrongly Agree). Each table then reported out on one of the traits and the indicators they came up with. All tables had a scribe, and we collected the resulting list of indicators and collated them into descriptors for each point on the rubric scales. Please see the attached copy of the RA assessment rubric for the scale descriptors.

A particular difficulty with this method is that there is no real way to norm the RAs. The typical situation in norming a group of raters on a rubric is to have them each read several artifacts in common, apply the rubric, and then compare their ratings on each trait, including a calculation of interrater reliability. However, in this case, there is only one RA capable of rating each resident student, since each student has only one RA. Thus we turned to a group discussion of the meaning of the values on our scale as a proxy for full norming.

\section{Results}

As of this writing, we now have four semesters of RA assessments, each including over I,, 00 students, and we have the first semester assessments of 673 freshmen. The first question that we had when we started this project was whether the RAs could in fact provide meaningful measurements and provide meaningful assessment data to the institution. While this method of assessment of student engagement has some obvious advantages of generating large amounts of identifiable data at very low cost, if the RAs do not provide us with careful and considered judgments about their residents, the data would be of little value.

First, we found that the assessment scores provided by the RAs are consistently skewed to the Agree/Strongly Agree end of the scale. Figures I and 2, taken from the fall 2008 assessment, are typical of each of the four semesters' data. RAs appear to be reluctant to score their residents at the Disagree end of the scale but do appear to make distinctions between Agree and Strongly Agree. We do not know if this skewed distribution is a result of reluctance on the part of our RAs to be harsh critics of their residents (a form of assessment inflation) or that the residents themselves are generally engaged and have good relationships with their RAs.

To evaluate the validity of these data we have turned to two data sources: student grades and student retention. 


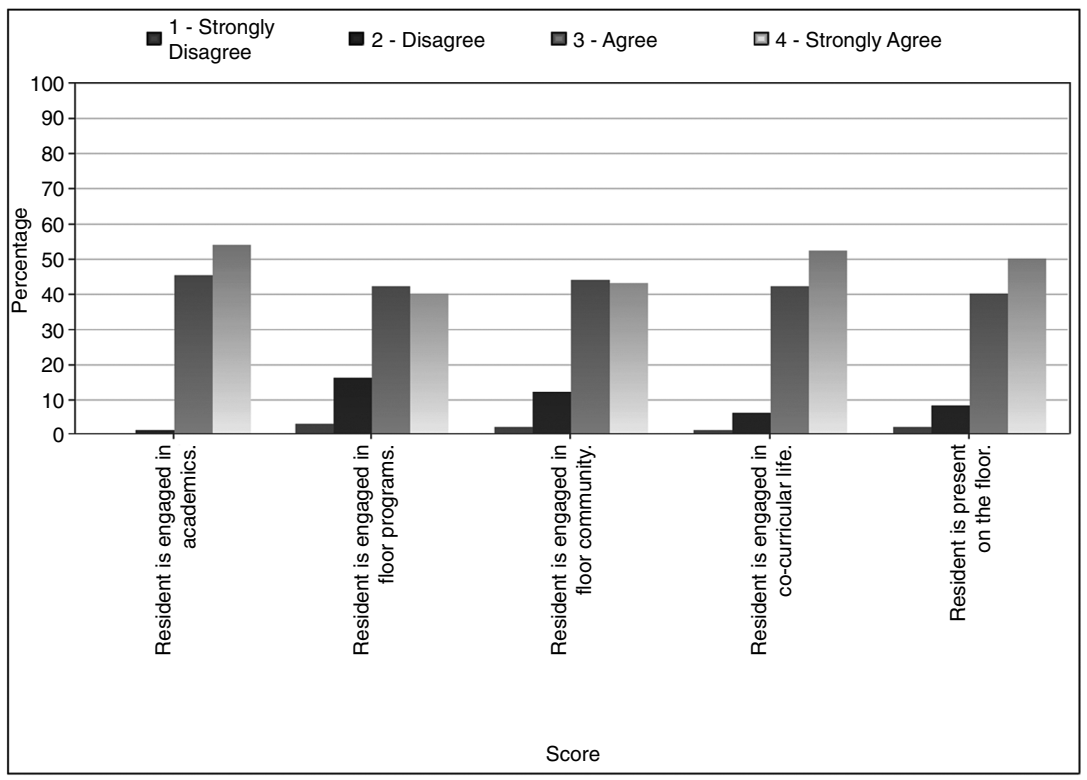

FIG I. Resident engagement

Note: Courses Reporting: 57. Students: 1,768.

Source: Chart generated by the Mentor Assessment Reporting System.

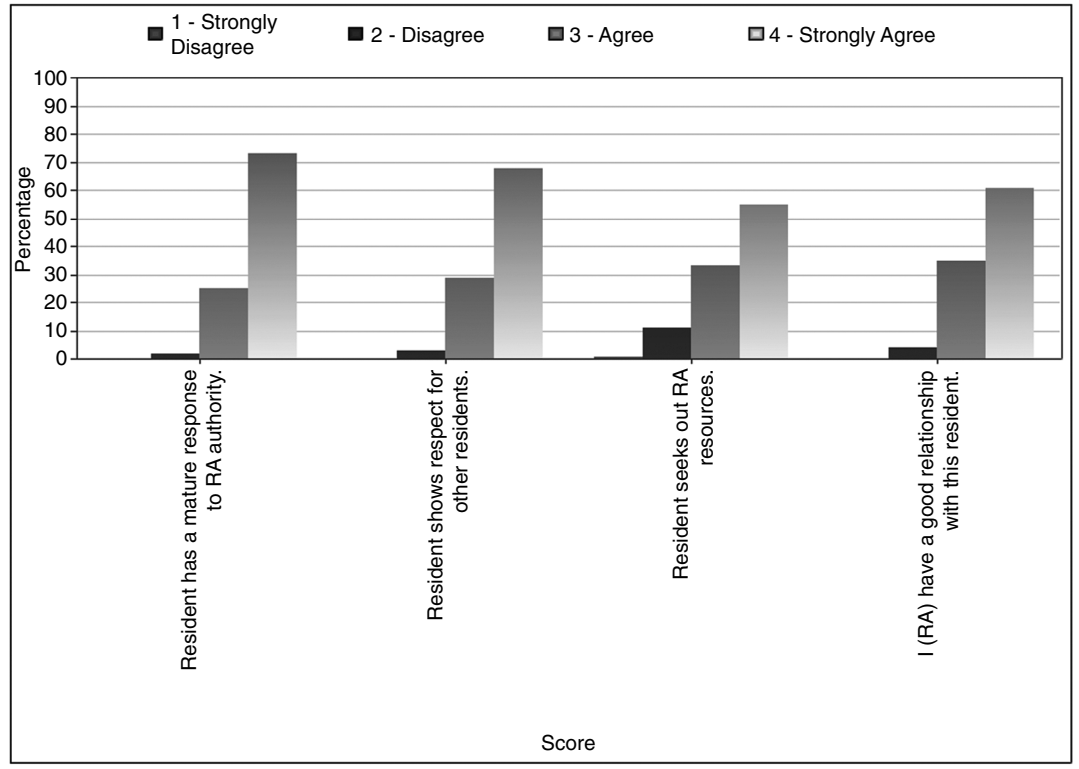

FIG 2. Resident relationship

Note: Courses Reporting: 57. Students: I,767.

Source: Chart generated by the Mentor Assessment Reporting System. 


\section{Student Grades}

The Mentor system has two reports that are built into the Student Assessment Reporting System. One report calculates the term grade-point average (GPA) for all students receiving each score on the scale (see fig. 3).

As figure 3 shows (Spring 2009), the numbers of students assessed at the Disagree or Strongly Disagree level on academic engagement is too low to draw any specific inference about the relationship of the RAs' assessment to their residents' academic performance as measured by GPA. In this case we can collapse the Strongly Disagree and Disagree scores together (see fig. 4).

Collapsing Strongly Disagree and Disagree together increases the number of students to over thirty and allows for a T-test of the GPA averages. In each case the GPA averages of the groups are sufficiently distinct to demonstrate a significant difference. This result is consistent across all four semesters of RA assessments. We ran an ANOVA on the entire four-semester data set against the term GPA for each student with a resulting significance of .o००.

Although the RA assessments of their residents' academic engagement shows a strong relationship to their residents' academic performance

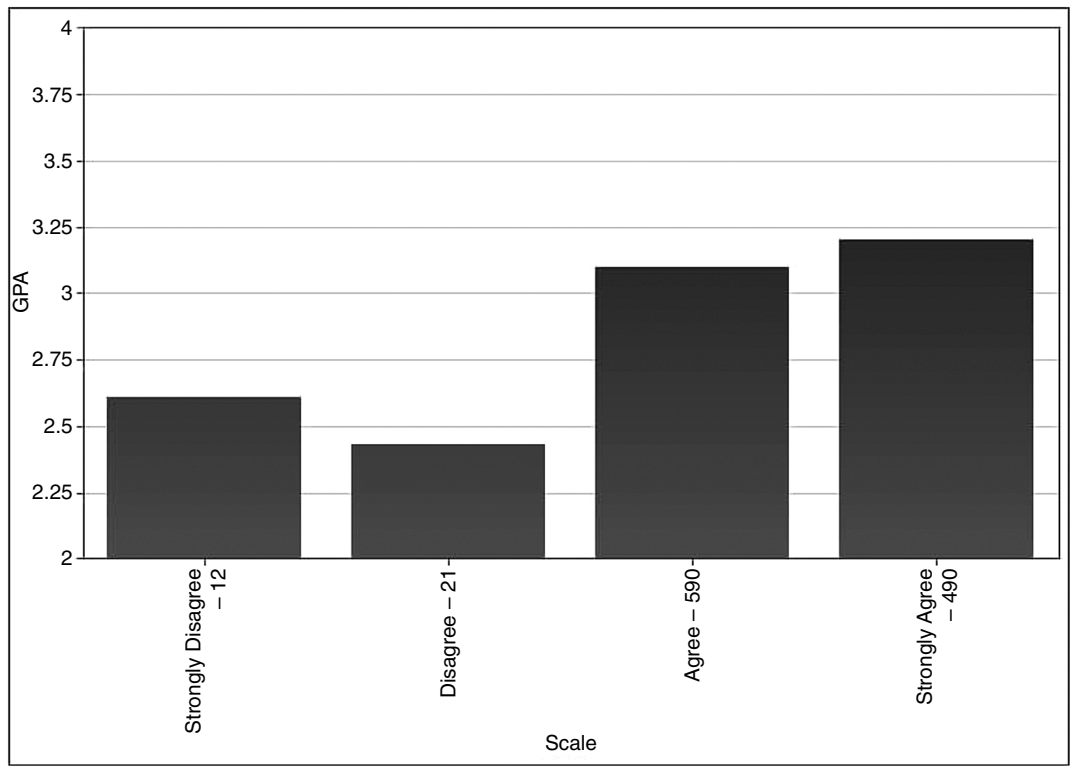

FIG 3. RA assessment results: Comparison to resident term GPA

Notes: Resident engagement: Resident is engaged in academics. GPA-student's overall grade point average, scale from 0-4. 


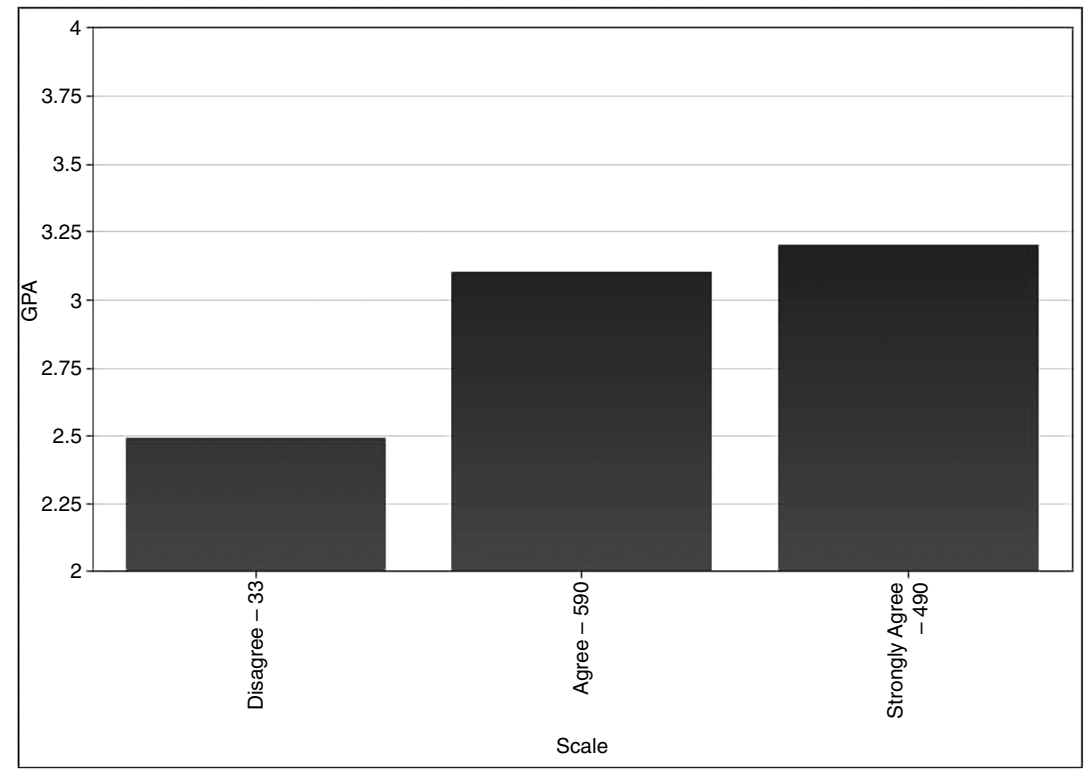

FIG 4. RA assessment results: Comparison to resident term GPA

Notes: Resident engagement: Resident is engaged in academics.

as measured by grades, it is important to keep in mind that "academic engagement" is not the same thing as academic performance. One can easily imagine students who are engaged in their studies and yet struggle to get high grades. The problem is also complicated by compression at the top on both the RA assessments (95\% of the RA assessments of academic engagement are in the Agree-Strongly Agree range), but also by grade inflation in general.

When we look at the same analyses of GPAs across each of the other eight traits on the rubric, we find no significant difference between the averages of Agree vs. Strongly Agree, but on every trait a significant difference in the GPAs of Agree versus the Strongly Disagree + Disagree groups, with the exception of the "Resident respects other residents" trait, where the trend was in this direction but the $p$ value just over the .05 interval. The conclusion that we draw from these comparisons is that residents who score on the Disagree side of the RA assessment rubric tend to perform less well academically.

This is a significant result for this project. First, it suggests that resident disengagement with academics, floor community, co-curricular activities, and their relationship to the RA all point to lower academic performance and this is consistent with the conclusions of Kuh noted in the introduction. 
The data do not, of course, tell us whether these disengaged students would perform better academically if they were more engaged. And clearly, we do not need the RAs to tell us whether students are performing well academically, since we have grades that presumably are an indicator of this. But insofar as academic engagement is distinct from academic performance, the RA data do allow us to identify students who are both academically disengaged and not performing well. It is certainly possible that we would target advising and counseling resources to these students in an effort to assist them in becoming more engaged in the university community and hopefully thereby better learners overall.

This is precisely how these data are now being used. Each residence hall has an area coordinator, a Residence Life professional staff member responsible for managing the RAs, developing programming, and working with the students. The area coordinators have access to a Mentor report that shows them aggregate data on each floor in their building and a student-bystudent report of the assessment data. The report highlights residents with low scores on any one trait on the rubric and who have an overall average score below Agree (see fig. 5).

Figure 5 shows a portion of one area coordinator's report on a single floor. While the student, Keith, appears to be not particularly engaged in the floor community and does not seem to have a good relationship to the RA (item 9), he appears to be doing well academically. On the other hand, Christopher appears radically disengaged from the floor community and alienated from the RA and other residents and is not doing so well academically. Both Christopher and Keith might benefit from a conversation with the area coordinator. The area coordinator may find roommate issues, disciplinary issues, or any of a variety of other factors at work here. The RA assessment data provides an opportunity to intervene early and at least investigate with individual students who appear to be at risk what issues the institution might be able to address.

\begin{tabular}{|c|c|c|c|c|c|c|c|c|c|c|c|c|}
\hline Name: & Term GPA: & Major: & Avg: & 1. & 2. & 3. & 4. & 5. & 6. & 7. & 8. & 9. \\
\hline Keith $x x x$ & 3.10 & BUSU & 2.4 & 3 & 3 & 2 & 2 & 2 & 3 & 3 & 1 & 2 \\
\hline Anthony $x x x$ & 2.87 & сOMM & 2.9 & 3 & 2 & 3 & 4 & 3 & 3 & 3 & 2 & 3 \\
\hline George $x x x$ & 2.19 & INBU & 3.5 & 3 & 3 & 4 & 3 & 4 & 4 & 3 & 4 & 4 \\
\hline Christopher xxx & 2.00 & FNCE & 1.1 & 1 & 2 & 1 & 1 & 1 & 1 & 1 & 1 & 1 \\
\hline Brian $x x x$ & 3.14 & BUSU & 3.5 & 3 & 3 & 4 & 3 & 4 & 4 & 3 & 4 & 4 \\
\hline Derek xxx & 2.46 & MATH & 2.6 & 3 & 3 & 3 & 3 & 2 & 3 & 3 & 1 & 2 \\
\hline Michael xxx & 2.82 & BUSU & 2.8 & 3 & 2 & 3 & 2 & 3 & 3 & 3 & 3 & 3 \\
\hline
\end{tabular}

FIG 5. Residents with low scores on any one rubric 


\section{Retention}

An important institutional indicator is retention of students. We ran crosstabs in SPSS, looking at retention as a function of each of the nine traits on the RA assessment rubric. We found significant but generally weak relationships between retention and academic engagement across all four semesters of assessments collected so far. We used a chi-square test and looked at the contingency co-efficient as a measure of the strength of the relationship (see table I).

Notice that the contingency coefficient is higher for the two spring semesters. We suspect that this is due to the fact that students who leave the university tend to do so at the end of the academic year rather than at the end of the fall semester.

Only one other trait demonstrated a significant relationship to retention across all four semesters (see table 2). We found significant relationships between retention and several other assessment traits, but none as strong as that with academic engagement and none that were consistent across all four semesters of this project. The "Resident is engaged in floor community" trait was significant across the last three semesters but not in the original pilot semester with the freshmen.

While the relationship is not strong-the contingency coefficient hovers in the .7-.I4 range wherever we find significance in the chi-square, this retention data coupled with the relationship to grades suggests that overall

TABLE I. Retention $\times$ academic engagement

\begin{tabular}{lcc}
\hline Term & $\chi$-Squared Sig. & Contingency Coefficient \\
\hline Spring 08 & .001 & .14 \\
Fall 08 & .019 & .067 \\
Spring 09 & .000 & .13 \\
Fall 09 & .011 & .073 \\
\hline
\end{tabular}

TABLE 2. Resident is engaged in co-curricular life

\begin{tabular}{lcc}
\hline Term & $\chi$-Squared Sig. & Contingency Coefficient \\
\hline Spring 08 & .018 & .108 \\
Fall 08 & .008 & .073 \\
Spring 09 & .000 & .118 \\
Fall 09 & .027 & .066 \\
\hline
\end{tabular}


the RAs' perceptions of their residents are not arbitrary and that they can in some cases identify for us students at risk. We also can conclude that their assessments of their residents on each trait are probably reasonable indicators of the engagement and/or relationship that each resident exhibits in the residence halls.

As of this writing, our area coordinators are initiating conversations with those students in their buildings who have been identified by their RA assessments as less engaged academically and in co-curricular and floor community life. These conversations will not be directly about the RA assessment scores, but the RA assessment data provide the area coordinator with a general background with which to initiate a conversation to see what issues might be preventing the student from engaging more fully in the residence hall community. We are exploring the feasibility of asking the area coordinators to keep detailed notes on each resident with whom they have a conversation. Presently, they are simply noting in a log that a conversation took place.

We are also exploring when and how to present the RA assessment data on each student to future area coordinators and RAs. Providing the area coordinators with past RA assessment data may prompt them to reach out early to students who were less engaged in previous semesters. We are initially reluctant to present past RA assessment data to current RAs for fear that it may prejudice them either in their relationship to the student or bias their own assessment. On the other hand, RAs could also make special efforts to reach out to those residents who in the past have been less engaged.

\section{Conclusion}

Asking RAs to participate in an assessment of their residents provides several clear benefits: (I) the assessment rubric itself sets clear expectations in plain language for the goals RAs are working toward on their respective floors. (2) By the same token the rubric also sets out clear expectations to the residents themselves. (3) The RA assessment data appear to be a valid indicator of student engagement and they allow the institution to identify students who may benefit from additional counseling or attention. Whether this additional attention can improve these residents' experiences remains to be seen.

Looking forward, we plan to continue this program and plan some additional analyses of the data. We are in the process of accessing the 
disciplinary data on each student and linking up this information to the RA assessment scores. We will also be looking at additional data sets, such as our NSSE, CIRP, and CSS surveys to investigate whether the RAs assessments match up with student self-reported survey answers.

\section{References}

Keeling, R. P. 2004. Learning Reconsidered. Washington, DC: National Association of Student Personnel Administrators.

Kuh, G. D., J. Kinzie, J. H. Schuh, E. J. Whitt, \& Associates. 2005. Student Success in College: Creating Conditions that Matter. San Francisco: Jossey-Bass.

Parks, S. 2000. Big Questions, Worthy Dreams. San Francisco: Jossey Bass. 